Article

\title{
Perioperative Myocardial Infarction/Myocardial Injury Is Associated with High Hospital Mortality in Elderly Patients Undergoing Hip Fracture Surgery
}

\author{
Carlo Rostagno ${ }^{1, *(\mathbb{D})}$, Alessandro Cartei ${ }^{1}$, Gaia Rubbieri ${ }^{1}$, Alice Ceccofiglio ${ }^{1}$, Agnese Magni ${ }^{1}$, \\ Silvia Forni ${ }^{2}$, Roberto Civinini ${ }^{3}$ and Alberto Boccaccini ${ }^{4}$ \\ 1 SODc Medicina Interna e Post-Chirurgica, AOU Careggi, 50136 Firenze, Italy; \\ carteia@aou-careggi.toscana.it (A.C.); rubbierig@aou-careggi.toscana.it (G.R.); \\ ceccofiglioa@aou-careggi.toscana.it (A.C.); agnese.magni@unifi.it (A.M.) \\ 2 Agenzia Regionale Sanità, 50136 Firenze, Italy; silvia.forni@ars.toscana.it \\ 3 SOD Ortopedia e Traumatologia AOU Careggi, 50136 Firenze, Italy; roberto.civinini@unifi.it \\ 4 SOD Anestesia e Rianimazione AOU Careggi, 50135 Firenze, Italy; boccaccinia@aou-careggi.toscana.it \\ * Correspondence: carlo.rostagno@unifi.it; Tel.: +39-0557948063
}

Received: 8 November 2020; Accepted: 9 December 2020; Published: 14 December 2020

\begin{abstract}
Cardiovascular complications in patients undergoing non-cardiac surgery are associated with longer hospital stays and higher in-hospital mortality. The aim of this study was to assess the incidence of in-hospital myocardial infarction and/or myocardial injury in patients undergoing hip fracture surgery and their association with mortality. Moreover, we evaluated the prognostic value of troponin increase stratified on the basis of peak troponin value. The electronic records of 1970 consecutive hip fracture patients were reviewed. Patients $<70$ years, those with myocardial infarction $<30$ days, and those with sepsis or active cancer were excluded from the study. Troponin and ECG were obtained at admission and then at 12, 24, and $48 \mathrm{~h}$ after surgery. Echocardiography was made before and within $48 \mathrm{~h}$ after surgery. Myocardial injury was defined by peak troponin I levels $>99$ th percentile. A total of 1854 patients were included. An elevated troponin concentration was observed in $754(40.7 \%)$ patients in the study population. Evidence of myocardial ischemia, fulfilling diagnosis of myocardial infarction, was found in 433 (57\%). ECG and echo abnormalities were more frequent in patients with higher troponin values; however, mortality did not differ between patients with and without evidence of ischemia. Peak troponin was between 0.1 and $1 \mu \mathrm{g} / \mathrm{L}$ in 593 (30.3\%). A total of $191(10 \%)$ had peak troponin I $\geq 1 \mu \mathrm{g} / \mathrm{L}$, and 98 died in hospital (5\%). Mortality was significantly higher in both groups with troponin increase $(\mathrm{HR}=1.37,95 \% \mathrm{CI} 1.1-1.7, p<0.001$ for peak troponin I between 0.1 and $1 \mu \mathrm{g} / \mathrm{L} ; \mathrm{HR}=2.28,95 \%$ CI 1.72-3.02, $p<0.0001$ for peak troponin $\geq 1 \mu \mathrm{g} / \mathrm{L})$ in comparison to patients without myocardial injury. Male gender, history of coronary heart disease, heart failure, and chronic kidney disease were also associated with in-hospital mortality. Myocardial injury/infarction is associated with increased mortality after hip fracture surgery. Elevated troponin values, but not ischemic changes, are related to early worse outcome.
\end{abstract}

Keywords: myocardial ischemia; troponin; hip fracture

\section{Introduction}

The incidence of perioperative myocardial infarction (MI) in patients with non-cardiac surgery has been reported between $6 \%$ and $36 \%$ according to the diagnostic criteria used in different studies [1-3]. Definite diagnosis of MI according to fourth universal definition requires, other than rise and fall of troponin values, at least one of the following conditions: typical symptoms, new electrocardiographic changes suggesting ischemia, or new segmental left ventricular wall abnormalities [4]. Most patients 
with perioperative MI/myocardial injury are asymptomatic. Moreover, after non-cardiac surgery ECG monitoring and/or echocardiography are not routinely performed. Evidence of "myocardial injury" mainly relies on post-operative increase of troponin values [5], and the diagnosis of true MI is underestimated.

Even small troponin increases (above upper 99th percentile of normal reference population) are associated with prolonged hospitalization and increased short- and long-term mortality [6,7]. Several clinical conditions, such as pulmonary embolism, sepsis, renal failure, and acute respiratory failure, may cause troponin to increase; however, these conditions may be ruled out on clinical basis. Patients undergoing hip surgery have a high incidence of myocardial injury, and troponin increase is associated with poor prognosis [8-10]. In our institution, patients undergoing hip surgery are followed by a multidisciplinary group [11]. This organization allows us to routinely perform post-operative ECG and echocardiogram; therefore, troponin changes can be related with clinical and/or objective evidence of myocardial ischemia, allowing for a distinction to be made between MI and myocardial injury. The aim of the present study was to assess the incidence of perioperative MI or myocardial injury and their relative effects on in-hospital mortality in patients who underwent hip fracture surgery. Furthermore, we evaluated the relation between different degrees of peak troponin values and early outcome.

\section{Methods}

This study is part of a project of the Italian Health Ministry and Regione Toscana-RF-20102316600 — and was approved by the Ethical Committee of Regione Toscana. At admission, all patients gave signed informed consent in order to collect and analyze clinical data for research purposes. The study was conducted according to STROBE statements.

The primary endpoint of the study was to assess the incidence of perioperative MI and myocardial injury in patients undergoing hip fracture surgery and their relation to in-hospital mortality. A secondary endpoint was to evaluate the prognostic value of troponin increase stratified on the basis of peak troponin value. Finally, we evaluated the association of different clinical variables with early mortality in patients with perioperative $\mathrm{MI} /$ myocardial injury.

All patients with hip fracture referred to AOU Careggi Firenze within a five-year period were eligible for the study. At hospital admission, they underwent multidisciplinary clinical evaluation, as previously reported [11]. ECG and laboratory examination including troponin I assay were performed at admission. Siemens Dimension Vista ${ }^{\circledR}$ System Flex ${ }^{\circledR}$ reagent (Siemens Healthcare GmbH, Erlangen, Germany) was used for TnI assay. Troponin and ECG were repeated at 12, 24, and $48 \mathrm{~h}$ after surgery. Echocardiography was performed on all patients before surgery, and within $48 \mathrm{~h}$ thereafter in patients with troponin increase. Myocardial damage was defined by troponin I level above 99th percentile of normal distribution $(>0.1 \mu \mathrm{g} / \mathrm{L})$. Definite myocardial infarction was diagnosed on site by the two cardiologists of the group according the "fourth universal definition of myocardial infarction" [4]. Results were compared with patients with no myocardial injury (troponin I peak below $0.1 \mu \mathrm{g} / \mathrm{L}$ ). Exclusion criteria were age $<70$ years, recent myocardial infarction ( $<30$ days), sepsis, and active neoplastic disease. Finally, patients with diagnosis of takotsubo syndrome confirmed by absence of critical coronary stenosis at angiography were not included in the study. In the other patients, the increase in troponin, being an expression of an imbalance between myocardial oxygen demand and supply, was considered of ischemic origin.

Patients with troponin increase were stratified in two groups: the first with peak troponin between 0.1 and $1 \mu \mathrm{g} / \mathrm{L}$, and the second with peak troponin above $1 \mu \mathrm{g} / \mathrm{L}$. A cut-off value of $1 \mu \mathrm{g} / \mathrm{L}$ was used, since it was demonstrated to be a strong independent predictor of mortality [12].

Electronic records of patients were reviewed. The data set included demographic data, time to surgery, comorbidities-including atrial fibrillation, hypertension, diabetes mellitus, chronic renal failure (e.g., creatinine clearance $<30 \mathrm{~mL} / \mathrm{min}$ ), CAD, heart failure, oral anticoagulant therapy (e.g., assumption of antivitamin $\mathrm{K}$ or direct oral anticoagulant agents like dabigatran, apixaban, 
rivaroxaban, or edoxaban at the moment of trauma), bleeding, sepsis, history of neoplastic disease, and cognitive impairment-troponin values, and ECG and echocardiographic findings. There were no missing data.

\section{Statistical Analysis}

Categorical variables are reported as frequency and percentage. Values for continuous variables were given as the mean (+SD). Categorical variables were compared using chi-square or Fisher exact tests, while continuous variables were compared using Student's $t$-test. The relation of multiple demographic and clinical variables with clinical outcome in patients with troponin increase was assessed by logistic multivariate analysis performed using SPSS 18.0 (IBM, Armonk, NY, USA) or Stata 14.1 (Stata Corp, College Station, TX, USA) statistical software. A probability value of $<0.05$ was considered to be statistically significant.

\section{Results}

\subsection{Descriptive Results}

A total of 1970 patients with hip fracture were referred to the Trauma Centre of Careggi University Hospital between 1 January 2014 and 31 December 2018 (30\% male and 70\% female, mean age 84 years). According to criteria reported in Section 2, 108 were excluded from the study (Figure 1). Five patients had sepsis, 48 active cancer. None was diagnosed with acute pulmonary embolism, while the 86 patients who developed atrial fibrillation after surgery were included, since we cannot exclude a relation between the onset of arrhythmia and transient perioperative ischemia.

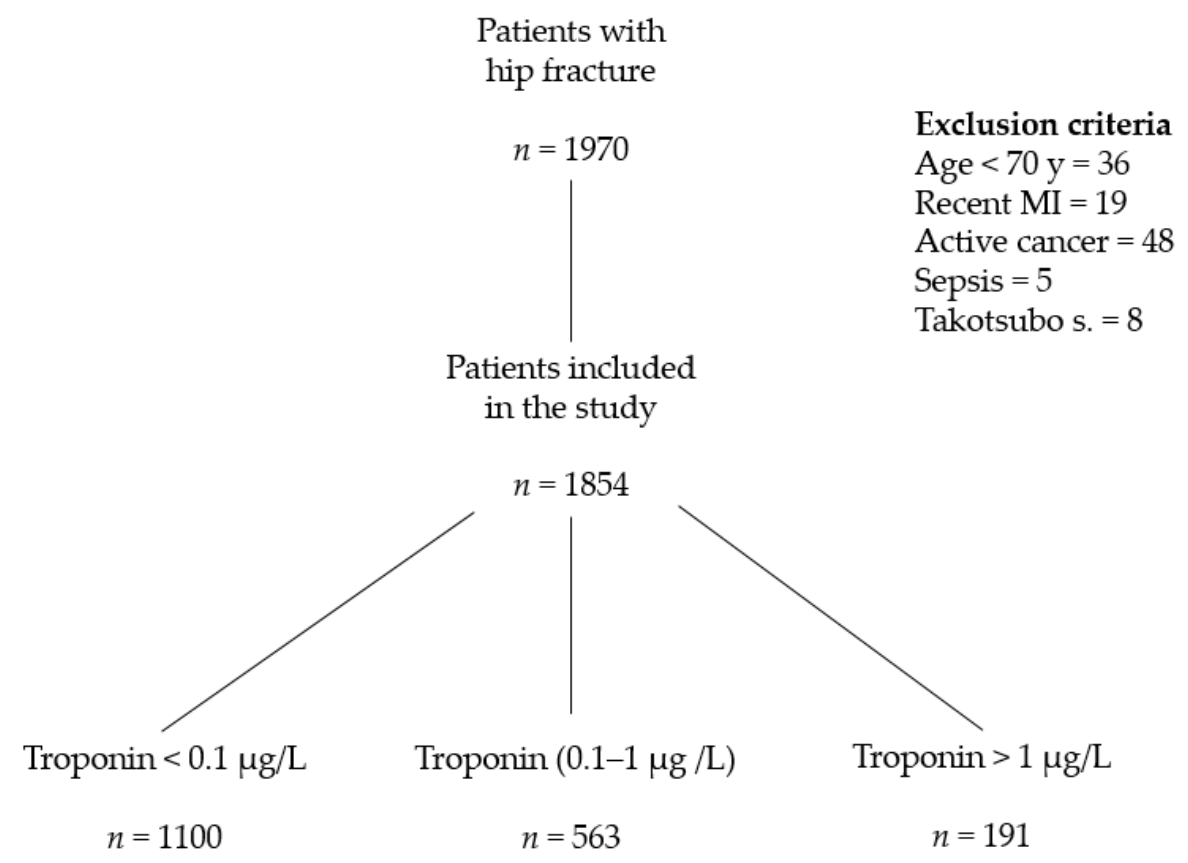

Figure 1. Patients included in the study.

Seven hundred fifty-four out of 1854 patients (40\%) had a peak troponin value above the upper 99th percentile of the reference population $(\mathrm{TnI}>0.1 \mu \mathrm{g} / \mathrm{L}$ ), while $593(30 \%)$ had peak troponin values between 0.1 and $1 \mu \mathrm{g} / \mathrm{L}$ (mean age $84.67 \pm 6.1$ years). Troponin peak $\mathrm{I} \geq 1 \mu \mathrm{g} / \mathrm{L}$ was found in $191(10 \%)$ patients (mean age $83.66 \pm 6.4$ years). Only five patients had typical chest pain; more common, but not specific signs, were hypotension and tachycardia.

History of coronary heart disease, heart failure, atrial fibrillation other than ongoing oral anticoagulation (antivitamin K or direct oral anticoagulants-DOACs), and antiplatelet treatment were 
significantly more frequent in patients with troponin $>1 \mu \mathrm{g} / \mathrm{L}$ in comparison to the other two groups. Moreover, in this group the relative prevalence of males was significantly higher $(82-43 \%, p<0.001)$ than in controls and in patients with lower troponin values. Incidence of major bleeding (bleeding requiring red blood cell transfusion) was more frequent in patients with troponin changes than in those with no myocardial injury. The three groups did not show differences regarding the incidence of chronic kidney disease, history of cancer, or presence of cognitive impairment (Table 1).

Table 1. Demographic and clinical characteristics of the three groups under study.

\begin{tabular}{ccccc}
\hline Clinical Characteristics & $\begin{array}{c}\text { No Myocardial } \\
\text { Injury } \boldsymbol{n = 1 1 0 0}\end{array}$ & $\begin{array}{c}\text { TnI 0.1-1 } \boldsymbol{\mu g} / \mathbf{L} \\
\boldsymbol{n}=\mathbf{5 6 3}\end{array}$ & $\begin{array}{c}\text { TnI } \geq \mathbf{1} \boldsymbol{\mu g} / \mathbf{L} \\
\boldsymbol{n}=\mathbf{1 9 1}\end{array}$ & $\boldsymbol{p}$-Value \\
\hline Mean age (SD) & $84.4 \pm 6.1$ & $84.67 \pm 7.1$ & $83.66 \pm 6.4$ & 0.527 \\
Male & $323(29 \%)$ & $167(29 \%)$ & $84(43 \%)$ & 0.0004 \\
Atrial fibrillation & $142(12.9 \%)$ & $109(16 \%)$ & $52(28 \%)$ & $<0.0001$ \\
Creatinine clearance $<30 \mathrm{~mL} / \mathrm{min}$ & $162(14 \%)$ & $86(15 \%)$ & $41(21 \%)$ & 0.0506 \\
Coronary disease & $131(12 \%)$ & $121(21 \%)$ & $93(48 \%)$ & $<0.0001$ \\
Heart failure & $92(8 \%)$ & $71(12 \%)$ & $37(19 \%)$ & $<0.0001$ \\
Oral anticoagulant treatment & $116(10 \%)$ & $82(14 \%)$ & $40(22 \%)$ & $<0.0001$ \\
History of cancer & $153(14 \%)$ & $106(18 \%)$ & $34(17 \%)$ & 0.1240 \\
Cognitive impairment & $265(24 \%)$ & $126(23 \%)$ & $52(27 \%)$ & 0.3795 \\
\hline
\end{tabular}

$\mathrm{SD}=$ standard deviation.

ST-T changes suggesting myocardial ischemia (evidence of new onset ST segment depression, or of inverted or biphasic $\mathrm{T}$ wave) were found in less than $40 \%$ of patients with troponin values between 0.1 and $1 \mu \mathrm{g} / \mathrm{L}$, and in $71 \%$ of patients with troponin peak $>1 \mu \mathrm{g} / \mathrm{L}$. The increase in troponin values was not associated with diagnostic changes at post-operative ECG in $65 \%$ of patients (Table 2).

Table 2. ECG and echocardiographic abnormalities in relation to degree of troponin increase.

\begin{tabular}{cccc}
\hline ECG Changes & $\begin{array}{c}\text { TnI } \mathbf{0 . 1 - 1} \boldsymbol{\mu g} / \mathrm{L} \\
\boldsymbol{n}=\mathbf{5 6 3}\end{array}$ & $\begin{array}{c}\text { TnI } \geq \mathbf{1} \boldsymbol{\mu g} / \mathbf{L} \\
\boldsymbol{n}=\mathbf{1 9 1}\end{array}$ & $\boldsymbol{p}$-Value \\
\hline Electrocardiogram & & & \\
Not diagnostic & $337(60 \%)$ & $54(28 \%)$ & $<0.0001$ \\
ST-T changes * & $219(39 \%)$ & $135(71 \%)$ & $<0.0001$ \\
ST elevation & $6(1 \%)$ & $2(1 \%)$ & 0.9 \\
Echocardiogram & & & \\
Not diagnostic & $276(49 \%)$ & $44(23 \%)$ & $<0.0001$ \\
LV wall motion Abnormalities & $214(38 \%)$ & $116(61 \%)$ & $<0.0001$ \\
Severe aortic stenosis & $73(13 \%)$ & $31(16 \%)$ & 0.2749 \\
Left ventricular EF (SD) & $51 \pm 6.2$ & $50.3 \pm 7$ & 0.456 \\
\hline * evidence of new onset ST segment depression, or of inverted or biphasic T wave. & LV = left ventricle; \\
EF = ejection fraction. &
\end{tabular}

Similarly, new left ventricular wall motion abnormalities were found more frequently in patients with peak troponin $1 \mu \mathrm{g} / \mathrm{L}$ ( $61 \%$ vs. $38 \%$ in patients with troponin values between 0.1 and $1 \mu \mathrm{g} / \mathrm{L}$ ). Left ventricular ejection fraction was not significantly different in the two groups. In both groups, the incidence of severe aortic stenosis (valve area $<1 \mathrm{~cm}^{2}$ ) was not negligible ( $13 \%$ and $16 \%$, respectively).

Definite diagnosis of MI, according to fourth universal definition, was made in 433 (23\%) patients after hip fracture surgery, while in 321 (17\%) troponin changes were not associated with evidence of ischemia (myocardial injury). Diagnosis of MI was significantly more frequent in patients with troponin $>1 \mu \mathrm{g} / \mathrm{L}$ (72 vs. $40 \%, p<0.001)$.

Thirty patients underwent early coronary angiography, on average within five days after hip surgery. In 29 , we found severe coronary artery disease (critical stenosis of at least two coronary vessels). The extent of coronary involvement was not related with the degree of troponin increase, although more frequently it was performed in patients with peak troponin $\geq 1 \mu \mathrm{g} / \mathrm{L}$. 


\subsection{In-Hospital Outcome}

Overall mortality during hospitalization was $98 / 1854$ patients (5\%). Mortality was significantly higher in both of the groups with increased troponin values in comparison to the control group. In fact, 39 patients (7\%) with troponin I values between 0.1 and $1 \mu \mathrm{g} / \mathrm{L}$ and $26(14 \%)$ with troponin I $\geq 1 \mu \mathrm{g} / \mathrm{L}$ died in hospital, in comparison to $32(2.9 \%)$ controls $(p<0.001)$. Death was due to cardiovascular causes (mainly refractory heart failure and sudden death) in $75 \%$ of cases, and occurred to $82 \%$ of patients with troponin increase in comparison to $40 \%$ of patients with no myocardial injury.

We did not find significant differences in mortality between patients with electrocardiographic and/or echocardiographic ischemic changes (patients with definite diagnosis of "myocardial infarction") or without them (patients with diagnosis of myocardial "injury") $(p=0.364)$. When groups were stratified according to peak troponin values, survival was lower in patients with myocardial injury and troponin peak between 0.1 and $1 \mu \mathrm{g} / \mathrm{L}$ (Table 3).

Table 3. In-hospital mortality (\%) per MI/myocardial injury (\%) with electrocardiographic and/or echocardiographic ischemic changes and troponin level.

\begin{tabular}{cccc}
\hline & \multicolumn{2}{c}{$\begin{array}{c}\text { MI/Myocardial Injury (\%) with Electrocardiographic } \\
\text { and/or Echocardiographic Ischemic Changes }\end{array}$} & \multirow{2}{*}{$p$-Value } \\
\cline { 2 - 3 } & Yes (433 Patients) & No (321 Patients) & \\
\hline $\operatorname{TnI} 0.1-1 \mu \mathrm{g} / \mathrm{L}$ (563 patients) & $13 / 290(4.5 \%)$ & $26 / 273(9.5 \%)$ & 0.0186 \\
\hline $\mathrm{TnI} \geq 1 \mu \mathrm{g} / \mathrm{L}$ (191 patients) & $21 / 143(14 \%)$ & $5 / 48(10 \%)$ & 0.4555 \\
\hline
\end{tabular}

Although hip fracture is largely prevalent in females (about 70\% in our study), the relative proportion of male patients was significantly higher in those with increased troponin I (43\%).

Table 4 indicates the main differences in clinical variables between patients discharged alive and those who died in hospital.

Table 4. Comparison of main comorbidities between patients with MI/MD who died in hospital or were discharged alive.

\begin{tabular}{cccc}
\hline Clinical Characteristics & $\begin{array}{c}\text { Patients Discharged } \\
\text { Alive }(\boldsymbol{n}=689)\end{array}$ & $\begin{array}{c}\text { Died } \\
(\boldsymbol{n}=65)\end{array}$ & $p$-Value \\
\hline Male gender & $200(29 \%)$ & $41(63 \%)$ & $<0.0001$ \\
$\begin{array}{c}\text { Time to surgery } \\
(<48 \text { h) }\end{array}$ & $510(74 \%)$ & $46(70 \%)$ & 0.383 \\
$\begin{array}{c}\text { Atrial fibrillation } \\
\text { Creatinine clearance } \\
<30 \text { mL/min }\end{array}$ & $179(26 \%)$ & $25(38 \%)$ & 0.02 \\
$\begin{array}{c}\text { Systolic pulmonary } \\
\text { Pressure }(>40 \text { mmHg) }\end{array}$ & $205(29 \%)$ & $20(30 \%)$ & 0.88 \\
Coronary artery disease & $187(27 \%)$ & $27(41 \%)$ & 0.005 \\
Heart failure & $83(10 \%)$ & $25(38 \%)$ & $<0.0001$ \\
Basic activities of daily & $265(38 \%)$ & $26(40 \%)$ & 0.79 \\
$\quad$ living $\leq 4$ & $85(11 \%)$ & $17(26 \%)$ & 0.002 \\
Oral anticoagulation & $165(21 \%)$ & $26(40 \%)$ & $<0.0001$ \\
\hline Bleeding & & & $<0.0001$ \\
\hline
\end{tabular}

Serum creatinine did not significantly change after surgery. The absolute decrease in hemoglobin concentration was not significantly different among groups; however, bleeding requiring transfusion was more frequent in patients who went on to die. Although these patients were more frequently under oral anticoagulation, before the intervention INR was below 1.3 in all patients being treated with warfarin, while in patients treated with DOACs we followed the current guidelines regarding the time from last administration to surgery $[13,14]$. 
Logistic multivariate analysis showed that male gender, peak troponin values, history of coronary heart disease, heart failure, atrial fibrillation, and chronic kidney disease were associated with in-hospital mortality in patients undergoing hip fracture surgery (Table 5).

Table 5. Factors related to early mortality at multivariate analysis.

\begin{tabular}{cccc}
\hline Clinical Characteristics & HR & $\mathbf{9 5 \%}$ CI & $p$-Value \\
\hline Age & 1.15 & $0.94-1.42$ & 0.07 \\
Gender $($ female $)$ & $\mathbf{0 . 5 7}$ & $\mathbf{0 . 4 7 - 0 . 6 8}$ & $<\mathbf{0 . 0 0 0 1}$ \\
Time to surgery $(<48 \mathrm{~h})$ & 0.95 & $0.89-1.05$ & 0.398 \\
Creatinine clearance $<30 \mathrm{~mL} / \mathrm{min}$ & $\mathbf{9 . 7}$ & $\mathbf{1 . 9}-\mathbf{3 3}$ & $<\mathbf{0 . 0 0 0 1}$ \\
Peak troponin $0.1-1 \mu \mathrm{g} / \mathrm{L}$ & $\mathbf{1 . 3 7}$ & $\mathbf{1 . 1}-\mathbf{1 . 7}$ & $\mathbf{0 . 0 0 0 5}$ \\
Peak troponin $>1 \mu \mathrm{g} / \mathrm{L}$ & $\mathbf{2 . 2 8}$ & $\mathbf{1 . 7 2}-\mathbf{3 . 0 2}$ & $<\mathbf{0 . 0 0 0 1}$ \\
Systolic pulmonary artery pressure $>40 \mathrm{mmHg}$ & 1.04 & $0.88-1.10$ & 0.15 \\
History of coronary artery disease & $\mathbf{5 . 3}$ & $\mathbf{1 . 0 3 - 2 5 . 4}$ & $\mathbf{0 . 0 4}$ \\
Atrial fibrillation & 1.21 & $0.78-8$ & 0.35 \\
Basic Activities of Daily Living $\leq 4$ & 0.98 & $0.68-1.41$ & 0.935 \\
Heart failure & $\mathbf{1 . 0 5}$ & $\mathbf{1 . 0 1 - 1 . 0 9}$ & $\mathbf{0 . 0 0 8 1}$ \\
Bleeding & 1.3 & $0.88-2.2$ & 0.17 \\
Oral anticoagulation & 1.28 & $0.79-3.12$ & 0.19 \\
\hline
\end{tabular}

Bold: statistical significant factors related to early mortality

\section{Discussion}

\subsection{Main Evidence and Comparison with Literature}

Results from the present investigation confirm the association of perioperative troponin peak with an increased mortality in patients who underwent hip fracture surgery. Nevertheless, we did not find significant difference in mortality between patients with definite MI (diagnosed according to the fourth universal definition of myocardial infarction) and patients with isolated myocardial injury (patients with troponin increase without ECG and/or echocardiographic changes). Male gender, history of coronary heart disease, heart failure, atrial fibrillation, and chronic kidney disease were associated with an increased risk of early mortality in patients with myocardial infarction/myocardial damage.

Perioperative MI significantly affects length of hospitalization and hospital mortality in patients undergoing non-cardiac surgery [1-3,14]. Troponin measurement is currently recommended in high-risk patients after non-cardiac surgery [15-18]. Several investigations demonstrated that troponin increase is independently related to early and long-term mortality [19-21]. However, in absence of electrocardiographic monitoring and/or echocardiography, troponin increase was also frequently related to several causes other than ischemic myocardial injury (mainly pulmonary embolism, sepsis, renal failure, and acute respiratory failure).

Elderly patients undergoing surgery for hip fracture are at particular risk due to aging and comorbidities. Surgical treatment of hip fracture within $48 \mathrm{~h}$ from trauma is associated with higher probability of functional recovery and decrease of complication rate and overall mortality [22,23].

After surgery for hip fracture, the incidence of perioperative MI/myocardial injury ranges from $6 \%$ to $36 \%$ according to diagnostic criteria adopted.

In a retrospective study from Olmsted County, Minnesota [24], incidence of perioperative MI was $14 \%$. Most patients did not experience ischemic symptoms, and required cardiac biomarkers for the diagnosis. In-hospital mortality was $14 \%$. In the study by Hietala et al. [9], TnT increased in $35.5 \%$ of patients with hip fracture. Overall, 30-day mortality was $17 \%$ and increased to $24 \%$ in subgroup with values $>0.15 \mu \mathrm{g} / \mathrm{L}$. Troponin increase was the only independent predictor of 30-day mortality. Similarly, in the study by Fisher et al. [12], perioperative increase of troponin I $>0.06 \mu \mathrm{g} / \mathrm{L}$ proved to be an independent factor in length of hospital stay and need for long-term residential care facilities. Troponin I $>1 \mu \mathrm{g} / \mathrm{L}$ was a predictor of all-cause mortality with $98 \%$ specificity and $89 \%$ negative predictive value. 


\subsection{Diagnosis and Management}

Multidisciplinary management may allow to identify preoperatively high-risk patients and favor clinical stabilization, thus improving safety of early surgery. In the postoperative period, the aim of this model is to limit, identify, and treat clinical complications. A multidisciplinary model has been employed in our teaching hospital since 2011. We conceived several clinical protocols, including one for diagnosis of perioperative MI/myocardial injury. Implementation of this multidisciplinary team was associated with a significant decrease in perioperative mortality [25].

The main novelty of the present investigation in comparison to previous studies was that our model, in which patients were followed by internal medicine specialists/cardiologists in the perioperative period, allowed for a more accurate differential diagnosis between definite MI and myocardial injury.

Overall incidence of MI according to the fourth universal definition was 19\%. Echocardiography allowed us to make a diagnosis of MI in about 30\% of subjects with troponin increase but with non-diagnostic changes at ECG.

Mortality was not significantly different between patients with and without definite diagnosis of MI. Otherwise, mortality was significantly different when patients were stratified according to peak troponin values. Troponin values $\geq 1 \mu \mathrm{g} / \mathrm{L}$ were associated with a two-fold higher mortality in comparison to patients with increase of a lower degree.

Identification of high-risk patients based on clinical history and preoperative evaluation may be helpful in the choice of surgical and anesthesia strategies to limit incidence of perioperative MI and related mortality. Medical treatment, aspirin, statin, and, recently, dabigatran [26-28] have been demonstrated to decrease mortality related to perioperative MI in non-cardiac surgery. Aspirin and statin decreased the risk for 30-day mortality among patients who had suffered a perioperative MI (adjusted odds ratios $0.54,95 \%$ CI $0.29-0.99$ and 0.26 , 95\% CI $0.13-0.54$, respectively) [26]. The design and results of the MANAGE study [26] do not allow definite conclusions about the usefulness of dabigatran in patients with postoperative troponin elevation after non-cardiac surgery (late enrollment, 35 days after surgery, low-risk profile, mean age 45 years, $14 \%$ history of coronary artery disease). The present study was not designed to evaluate medical interventions in order to improve the outcome in patients undergoing hip fracture surgery. Guidelines were followed (beta-blockers and antiplatelet drugs were not withdrawn before surgery in high-risk patients, and statin and ACE-I or ARB were maintained in patients with controlled/high blood pressure).

Diagnostic work-out in MI /myocardial injury after non-cardiac surgery is unusual, and the few studies have reported discordant data about the usefulness of early coronary angiography and revascularization [29,30]. The study of Parashar et al. [29] showed no benefit of early coronary revascularization in patients with postoperative MI after non-cardiac surgery. The outcome was poorer in particular in patients with major bleeding, chronic renal damage, and peripheral vascular disease. It must be emphasized that most patients had vascular, thoracic, and abdominal surgery. In our cohort, 30 patients underwent early coronary angiography. In 29 we found at least two coronary vessel diseases. We did not find a relation between degree of troponin increase and extension of coronary disease. This suggests that most patients with troponin increase have type II MI (myocardial injury) and severe atherosclerosis as the main pathogenetic mechanism of troponin release.

In a preliminary study from our group involving a small number of patients after hip surgery, early revascularization after perioperative myocardial infarction was associated with significant increase in one-year survival [28]. Larger studies are needed to assess the effects on early, in-hospital outcome.

\section{Limitations}

The main limitation of the present investigation was its retrospective design. Moreover, it was a single-center study including a relatively small number of patients and with a low number of events, although it must be underlined that most previous investigations of this topic had similar numerosity. Finally, troponin I concentrations were measured since hs-TnT has been available in our hospital only in the second half of 2019. At present, no studies directly compared standard TnI-TnT assay with 
hs-Tn in non-cardiac surgery. The higher sensitivity demonstrated in acute coronary syndromes must still be demonstrated in this setting. An investigation protocol has recently been submitted to the Ethical Committee of our hospital.

Nevertheless, a merit of this present study is that a definite protocol for preoperative evaluation of hip fracture patients and for diagnosis of perioperative $\mathrm{MI} /$ myocardial injury has been followed in our institution since 2014. This allowed a more accurate distinction between definite MI and myocardial injury. Due to organizational problems, extensive cardiologic follow-up with these patients has not been possible, and was limited to small subgroups. Therefore, in the whole population we were only able to analyze in-hospital outcome. Results from the present investigation may offer elements for further research on prevention of cardiac damage related to non-cardiac surgery. The finding of severe coronary artery disease in almost all patients who underwent coronary angiography may suggest coronary atherosclerosis as the main pathogenetic factor leading to troponin increase, and procedural interventions aimed to decrease the imbalance between oxygen demand and supply, as well as to plaque stabilization, may be hypothesized to decrease early mortality. We must agree that the relevance of these data is limited by the small number of patients who underwent coronary angiography.

\section{Conclusions}

Incidence of perioperative $\mathrm{MI} /$ myocardial injury after hip surgery was about $40 \%$, and a definite diagnosis of myocardial infarction according to the fourth universal definition was made in $23 \%$ of patients. Higher peak troponin I level is related to a worse outcome. In fact, in-hospital mortality was as high as $14 \%$ in patients with troponin I $>1 \mu \mathrm{g} / \mathrm{L}$, in comparison to $7 \%$ of those with increase of a lower degree. Otherwise, despite a tight protocol, we did not find significant differences in the outcomes between patients with definite MI and patients with myocardial injury. The diagnosis of MI might be slightly underestimated, however, since transient ECG changes may have been overlooked.

Future research should assess whether optimization of preoperative medical treatment, choice of anesthesia strategy, and decrease in intraoperative blood loss may limit incidence of perioperative $\mathrm{MI} /$ myocardial injury and related in-hospital deaths.

Author Contributions: Conceptualization, C.R. and A.B.; methodology, C.R.; software, S.F.; validation, C.R., S.F. formal analysis, C.R., S.F.; investigation, A.C. (Alessandro Cartei), G.R., A.C. (Alice Ceccofiglio); data curation, A.M., R.C.; writing—original draft preparation, C.R.; writing—review and editing, C.R., A.B. All authors have read and agreed to the published version of the manuscript.

Funding: The study is part of a project of Italian Health Ministry and Regione Toscana-RF-2010-2316600.

Conflicts of Interest: The authors declare no conflict of interest. The funders had no role in the design of the study; in the collection, analyses, or interpretation of data; in the writing of the manuscript, or in the decision to publish the results.

\section{References}

1. Puelacher, C.; Lurati Buse, G.; Seeberger, D.; Sazgary, L.; Marbot, S.; Lampart, A.; Espinola, J.; Kindler, C.; Hammerer, A.; Seeberger, E.; et al. Perioperative Myocardial Injury After Non-cardiac Surgery: Incidence, Mortality, and Characterization. Circulation 2018, 137, 1221-1232. [CrossRef]

2. van Waes, J.A.; Nathoe, H.M.; de Graaff, J.C.; Kemperman, H.; De Borst, G.J; Peelen, L.M.; Van Klei, W.A.; Buhre, W.F.; Kalkman, C.J.; Van Wolfswinkel, L.; et al. Myocardial injury after noncardiac surgery and its association with short-term mortality. Circulation 2013, 127, 2264-2271. [CrossRef]

3. Devereaux, P.J.; Xavier, D.; Pogue, J.; Guyatt, G.; Sigamani, A.; Garutti, I.; Leslie, K.; Rao-Melacini, P.; Chrolavicius, S.; Yang, H.; et al. Characteristics and short-term prognosis of perioperative myocardial infarction in patients undergoing noncardiac surgery: A cohort study. Ann. Intern. Med. 2011, 154, 523-528. [CrossRef]

4. Thygesen, K.; Alpert, J.S.; Jaffe, A.S.; Chaitman, B.R.; Bax, J.J.; Morrow, D.A.; White, H.D. Fourth Universal Definition of Myocardial nfarction (2018). J. Am. Coll. Cardiol. 2018, 72, 2231-2264. [CrossRef] [PubMed] 
5. Botto, F.; Alonso-Coello, P.; Chan, M.T.V.; Villar, J.C.; Xavier, D.; Srinathan, S.K.; Guyatt, G.; Graham, M.; Wang, C.Y.; Berwanger, O.; et al. Myocardial injury after noncardiac surgery: A large, international, prospective cohort study establishing diagnostic criteria, characteristics, predictors, and 30-day outcomes. Anesthesiology 2014, 120, 564-578. [PubMed]

6. Devereaux, P.J.; Szczeklik, W. Myocardial injury after non-cardiac surgery: Diagnosis and management. Eur. Heart J. 2019, 41, 3083-3091. [CrossRef] [PubMed]

7. Buse, G.L.; Manns, B.; Lamy, A.; Guyatt, G.; Polanczyk, C.A.; Chan, M.T.; Wang, C.Y.; Villar, J.C.; Sigamani, A.; Sessler, D.I.; et al. Troponin T monitoring to detect myocardial injury after non-cardiac surgery: A cost-consequence analysis. Can. J. Surg. 2018, 61, 185-194. [CrossRef] [PubMed]

8. Gupta, B.P.; Huddleston, J.M.; Kirkland, L.L.; Huddleston, P.M.; Larson, D.R.; Gullerud, R.E.; Burton, M.C.; Rihal, C.S.; Wright, R.S. Clinical Presentation and Outcome of Perioperative Myocardial Infarction in Very Elderly Following Hip Fracture Surgery. J. Hosp. Med. 2012, 7, 713-716. [CrossRef]

9. Hietala, P.; Strandberg, M.; Strandberg, N.; Gullichsen, E.; Airaksinen, K.E. Perioperative myocardial infarctions are common and often unrecognized in patients undergoing hip fracture surgery. J. Trauma Acute Care Surg. 2013, 74, 1087-1091. [CrossRef] [PubMed]

10. Thiagrajah, S.; Fenton, A.; Sivardeen, Z.; Stanley, D. The management and mortality of patients undergoing hip fracture surgery following recent acute myocardial infarction. Acta Orthop. Belg. 2011, 77, 626-663.

11. Rostagno, C.; Buzzi, R.; Campanacci, D.; Boccacini, A.; Cartei, A.; Virgili, G.; Belardinelli, A.; Matarrese, D.; Ungar, A.; Rafanelli, M.; et al. In Hospital and 3-Month Mortality and Functional Recovery Rate in Patients Treated for Hip Fracture by a Multidisciplinary Team. PLoS ONE 2016, 11, e0158607. [CrossRef] [PubMed]

12. Fisher, A.A.; Southcott, E.N.; Goh, S.L.; Srikusalanukul, W.; Hickman, P.E.; Davis, M.W.; Potter, J.M.; Budge, M.M.; Smith, P.N. Elevated serum cardiac troponin I in older patients with hip fracture: Incidence and prognostic significance. Arch. Orthop. Trauma Surg. 2008, 128, 1073-1079. [CrossRef] [PubMed]

13. Steffel, J.; Verhamme, P.; Potpara, T.S.; Albaladejo, P.; Antz, M.; Desteghe, L.; Haeusler, K.G.; Oldgren, J.; Reinecke, H.; Roldan-Schilling, V.; et al. The 2018 European Heart Rhythm Association Practical Guide on the use of non-vitamin $\mathrm{K}$ antagonist oral anticoagulants in patients with atrial fibrillation. Eur Heart J. 2018, 39, 1330-1393. [CrossRef] [PubMed]

14. Douketis, J.D.; Spyropoulos, A.C.; Duncan, J.; Carrier, M.; Le Gal, G.; Tafur, A.J.; Vanassche, T.; Verhamme, P.; Shivakumar, S.; Gross, P.L.; et al. Perioperative Management of Patients with Atrial Fibrillation Receiving a Direct Oral Anticoagulant. JAMA Intern. Med. 2019, 179, 1469-1478. [CrossRef] [PubMed]

15. Smilowitz, N.R.; Beckman, J.A.; Sherman, S.E.; Berger, J.S. Hospital Readmission After Perioperative Acute Myocardial Infarction Associated with Non-cardiac Surgery. Circulation 2018, 137, 2332-2339. [CrossRef]

16. Fleisher, L.A.; Fleischmann, K.E.; Auerbach, A.D.; Barnason, S.A.; Beckman, J.A.; Bozkurt, B.; Davila-Roman, V.G.; Gerhard-Herman, M.D.; Holly, T.A.; Kane, G.C.; et al. 2014 ACC/AHA guideline on perioperative cardiovascular evaluation and management of patients undergoing noncardiac surgery: Executive summary: A report of the American College of Cardiology/American Heart Association Task Force on Practice Guidelines. Circulation 2014, 130, 2215-2245. [CrossRef]

17. Kristensen, S.D.; Knuuti, J.; Saraste, A.; Anker, S.D.; Bøtker, H.E.; De Hert, S.; Ford, I.; Gonzalez-Juanatey, J.R.; Gorenek, B.; Heyndrickx, G.R.; et al. 2014 ESC/ESA Guidelines on non-cardiac surgery: Cardiovascular assessment and management: The Joint Task Force on non-cardiac surgery: Cardiovascular assessment and management of the European Society of Cardiology (ESC) and the European Society of Anaesthesiology (ESA). Eur. Heart J. 2014, 35, 2383-2431. [CrossRef]

18. Duceppe, E.; Parlow, J.; MacDonald, P.; Lyons, K.; McMullen, M.; Srinathan, S.; Graham, M.; Tandon, V.; Styles, K.; Bessissow, A.; et al. Canadian Cardiovascular Society Guidelines on Perioperative Cardiac Risk Assessment and Management for Patients Who Undergo Noncardiac Surgery. Can. J. Cardiol. 2017, 33, 17-32. [CrossRef]

19. Levy, M.; Heels-Ansdell, D.; Hiralal, R.; Bhandari, M.; Guyatt, G.; Yusuf, S.; Cook, D.; Villar, J.C.; McQueen, M.; McFalls, E.; et al. Prognostic value of troponin and creatine kinase muscle and brain isoenzyme measurement after noncardiac surgery: A systematic review and meta-analysis. Anesthesiology 2011, 114, 796-806. [CrossRef]

20. Hietala, P.; Strandberg, M.; Kiviniemi, T.; Strandberg, N.; Airaksinen, J. Usefulness of troponin T to predict short-term and long-term mortality in patients after hip fracture. Am. J. Cardiol. 2014, 114, $193-197$. [CrossRef] 
21. Izhaki, A.; Slesarenko, Y.; Boaz, M.; Haimovich, E.; Rozenman, Y. Cardiac troponin T: An important predictor of late death and myocardial infarction following hip fracture: An eight year prospective observational cohort study. Eur. J. Orthop. Surg. Traumatol. 2011, 21, 243-249. [CrossRef]

22. Grimes, J.P.; Gregory, P.M.; Noveck, H.; Butler, M.S.; Carson, J.L. The effects of time-to-surgery on mortality and morbidity in patients following hip fracture. Am. J. Med. 2002, 112, 702-709. [CrossRef]

23. Shiga, T.; Wajima, Z.; Ohe, Y. Is operative delay associated with increased mortality of hip fracture patients? Systematic review, meta-analysis, and meta-regression. Can. J. Anaesth. 2008, 55, 146-154. [CrossRef] [PubMed]

24. Huddleston, J.M.; Gullerud, R.E.; Smither, F.; Huddleston, P.M.; Larson, D.P.; Phy, M.P.; Melton, L.J., III; Roger, V.L. Myocardial infarction after hip fracture repair: A population-based study. J. Am. Geriatr. Soc. 2012, 60, 2020-2026. [CrossRef] [PubMed]

25. Rostagno, C.; Cartei, A.; Civinini, R.; Prisco, D. Hip fracture unit: Beyond orthogeriatrics. Intern. Emerg. Med. 2018, 13, 637-639. [CrossRef]

26. POISE Study Group. Effects of extended-release metoprolol succinate in patients undergoing non-cardiac surgery (POISE trial): A randomised controlled trial. Lancet 2008, 371, 1839-1847. [CrossRef]

27. Foucrier, A.; Rodseth, R.; Aissaoui, M.; Ibanes, C.; Goarin, J.-P.; Landais, P.; Coriat, P.; Le Malnach, Y. The long-term impact of early cardiovascular therapy intensification for postoperative troponin elevation after major vascular surgery. Anesth. Analg. 2014, 119, 1053-1063. [CrossRef]

28. Devereaux, P.J.; Duceppe, E.; Guyatt, G.; Tandon, V.; Rodseth, R.; Biccard, B.M.; Xavier, D.; Szczeklik, W.; Meyhoff, C.S.; Vincent, J.; et al. Dabigatran in patients with myocardial injury after non-cardiac surgery (MANAGE): An international, randomised, placebo-controlled trial. Lancet 2018, 391, 2325-2334. [CrossRef]

29. Parashar, A.; Agarwal, S.; Krishnaswamy, A.; Sud, K.; Poddar, K.L.; Bassi, M.; Ellis, S.; Tuzcu, E.M.; Menon, V.; Kalpadia, S. Percutaneous Intervention for Myocardial Infarction After Noncardiac Surgery: Patient Characteristics and Outcomes. J. Am. Coll. Cardiol. 2016, 68, 329-338. [CrossRef]

30. Rostagno, C.; Peris, A.; Polidori, G.L.; Ranalli, C.; Carteti, A.; Civinini, R.; Boccaccini, A.; Prisco, D.; Innocenti, M.; Di Mario, C. Perioperative myovardial infarction in elderly patients with hip fracture. Is there a role for early coronary angiography? Int. J. Cardiol. 2019, 284, 1-5. [CrossRef]

Publisher's Note: MDPI stays neutral with regard to jurisdictional claims in published maps and institutional affiliations.

(C) 2020 by the authors. Licensee MDPI, Basel, Switzerland. This article is an open access article distributed under the terms and conditions of the Creative Commons Attribution (CC BY) license (http://creativecommons.org/licenses/by/4.0/). 